\title{
Heterotopic Ossification Following Cervical Total Disc Replacement: latrogenic or Constitutional?
}

\author{
Hyun-Jin Cho, Myung-Hoon Shin, Jung-Woo Huh, \\ Kyeong-Sik Ryu, Chun-Kun Park \\ Departments of Neurosurgery, Seoul St. Mary Hospital, The Catholic University, Seoul, Korea
}

\begin{abstract}
Objective: To elucidate etiological factors of heterotopic ossification $(\mathrm{HO})$ by evaluating retrospectively if $\mathrm{HO}$ is a unique finding following cervical total disc replacement (CTDR) or a finding observable following an anterior cervical interbody fusion (ACIF). Methods: The authors had selected 87 patients who underwent anterior cervical surgery (TDR or ACIF), and could be followed up more than 24 months. A cervical TDR was performed using a Bryan disc or a ProDisc-C and an ACIF using a standalone cage or fibular allograft with a plate and screws system. The presence of $\mathrm{HO}$ was determined by observing plain radiography at the last follow up. The relation between $\mathrm{HO}$ occurrence and specific preoperative radio- logical findings (osteophyte and calcification of posterior longitudinal ligament (PLL)) at the index level was investigated.

Results: Cervical TDR was performed in 40 patients (43 levels) and ACIF in 47 patients (54 levels). At the final radiographs, HO was demonstrated at 27 levels (TDR-Bryan; 8/18, TDR-Prodisc-C; 12/25, ACIF-cage alone; 7/29, and ACIF-plate screw; 0/25). Mean ROM at the last follow-up of each TDR subgroup were $7.8 \pm 4.7^{\circ}$ in Bryan, $3.89 \pm 1.77^{\circ}$ in Prodisc-C, and it did not correlated with the incidence of HO. Fusion status of ACIF groups was observed as 2 case of grade 1, 6 of grade 2, and 21 of grade 3 in cage alone subgroup, and no case of grade 1, 4 of grade 2, and 21 of grade 3 in plate screw subgroup. Fusion status in ACIF-cage alone subgroup was significantly related to the $\mathrm{HO}$ incidence. The preoperative osteophyte at the operated level observed in 27 levels, and HO was demonstrated in 12 levels (TDR-Bryan; 3/5, TDR-Prodisc-C; 2/3, ACIFcage alone; 7/11, and ACIF-plate screw; 0/8). Preoperative PLL calcification at the operated level was observed 22 levels, and $\mathrm{HO}$ was defined at 14 levels (TDR-Bryan; 5/5, TDR-Prodisc-C; 4/5, ACIF-cage alone; 5/7, and ACIF-plate screw; 0/5). The evidence of preoperative osteophyte and PLL calcification showed statistically significant relations to the occurrence of $\mathrm{HO}$.

Conclusion: $\mathrm{HO}$ was observed in both TDR and ACIF groups. HO was more frequently occurred in TDR group regardless of prosthesis type. In ACIF group, only cage alone subgroup showed $\mathrm{HO}$, with relation to fusion status. Preoperative calcification of longitudinal ligaments and osteophyte were strongly related to the occurrence of $\mathrm{HO}$.
\end{abstract}

Key Words: Degenerative cervical spine disease $\cdot$ Cervical arthroplasty $\cdot$ Heterotopic ossification $\cdot$ Bryan disc $\cdot$ Prodisc-C $\cdot$ Cervical athrodesis

\section{INTRODUCTION}

The definition of heterotopic ossification $(\mathrm{HO})$ is the formation of ectopic bone outside the skeletal system where bone formation does not occur normally. With rising the various

- Received: July 24, 2012 - Revised: September 18, 2012

- Accepted: September 25, 2012

Corresponding Author: Kyeong-Sik Ryu, MD

Department of Neurosurgery, Seoul St. Mary's Hospital, 505 Banpo-Dong,

Seocho-Gu, Seoul 137-701, Korea

Tel: +82-2-2258-6127, Fax: +82-2-594-4248

Email: nsdoc35@catholic.ac.kr kinds of spinal motion preserving surgeries, spinal surgeons are also getting concerned with HO. Mc-Afee et al., firstly described and classified HO following lumbar total disc replacement $(\mathrm{TDR})^{10)}$. According to their report, the incidence of $\mathrm{HO}$ after lumbar TDR had ranged from $1.4 \%$ to $15.2 \%$. Following cervical TDR, the incidence of $\mathrm{HO}$ reported has shown a wide range from $7 \%$ to $56 \% \%^{7,15,19-21)}$.

Although the precise causal factors of $\mathrm{HO}$ are still unclear, mesenchymal cells originating from bone or muscle to osteoblasts would play a major role ${ }^{12}$. During the surgery, the manipulations of bone and muscle may provide an opportunity for mesenchymal cells to spread into wellvascularized surrounding soft tissue. Thus, during cervical TDR, trauma to the 
Table 1. The degree of fusion state based on dynamic X-ray of each arthrodesis method

\begin{tabular}{clc}
\hline \hline & Stand-alone cage & Allograft with plate screw system \\
\hline $\begin{array}{c}\text { Grade } 1 \\
\text { Grade } 2 \text { No motion or radiolucency above and below a device }\end{array}$ & $\begin{array}{c}\text { Any motion or radiolucency above and below a graft } \\
\text { device without definite bony bridge in the cage }\end{array}$ & $\begin{array}{c}\text { No motion and no radiolucency above and below graft without a defi- } \\
\text { nite bony bridge incorporated the graft and the adjacent endplates }\end{array}$ \\
$\begin{array}{ccc}\text { Grade } 3 \text { No motion and no radiolucency above and below } & \text { No motion and no radiolucency above and below graft with a defi- } \\
\text { device with definite bony bridge in the cage } & \text { nite bony bridge incorporated the graft and the adjacent endplates }\end{array}$ \\
\hline
\end{tabular}

longus colli and the remaining bone debris following bone works may predispose inevitable ectopic bone formation. However, if this hypothesis is applicable, there would be a same risk of $\mathrm{HO}$ occurrence in other kinds of anterior cervical surgeries. All anterior cervical surgeries with standard approach require similar manipulation of soft tissues and bone work, thus they has a same possibility to be caught in the HO.

This retrospective study is performed to observe the incidence of $\mathrm{HO}$ in different kinds of anterior cervical surgeries; TDR and anterior cervical interbody fusion using stand-alone cage or fibular allograft with a plate and screws system, and to identify etiological factors of $\mathrm{HO}$ in relation to the clinical and radiological findings.

\section{MATERIALS AND METHODS}

\section{Patients}

For the present study, the authors had gathered the records of 108 patients who underwent anterior cervical surgery for degenerative cervical spine diseases between April 2004 and October 2007. Among them, 87 patients could be followed up more than 24 months were enrolled. Other 21 patients were lost during follow-up by several reasons such as changing contact addresses, death, or pregnancy.

The surgeries consisted with cervical TDR using Bryan disc (Medtronic Sofamor Danek) or Prodisc-C (Synthes Spine) and anterior cervical interbody fusion (ACIF) using a RABEA (Signus Medical) stand-alone cage or fibular allograft with a plate and screws using Atlantis system (Medtronic Sofamor Danek). All operations were performed by a single senior surgeon (C.K.P.). According to each surgical procedure, the enrolled patients were classified into 4 groups; 'TDR-Bryan', 'TDRProdisc-C', 'ACIF-cage alone', and 'ACIF-plate screws group'. The cases of hybrid surgery which combined with TDR and arthrodesis were excluded in the present study.

\section{Assessment}

All radiological assessments were performed by observing plain cervical radiography. Images obtained at the preoperative were compared with those of the last follow up.
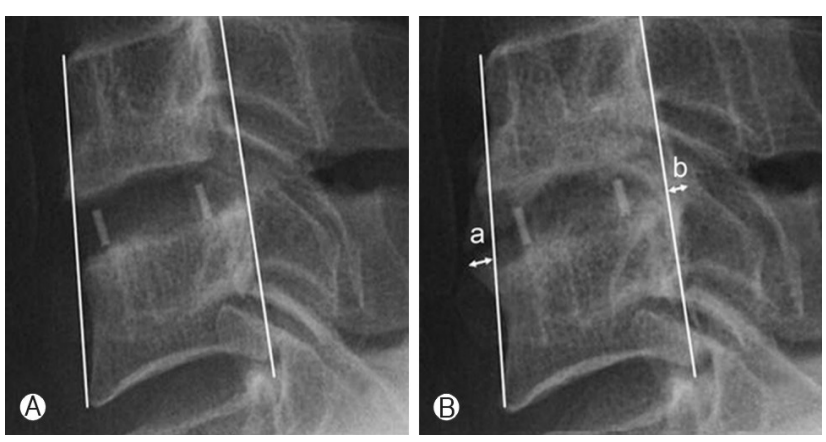

Fig. 1. Plain lateral radiographs showing how $\mathrm{HO}$ in $\mathrm{ACIF}$ group is determined in the lateral plane. If there is more than $1 \mathrm{~mm}$ of bone formation (width of ' $a$ ' or ' $b$ ') from the anterior or posterior outmost border of vertebral body on the last follow-up image (B) comparing to immediate post- operative one (A), this bone formation is defined as $\mathrm{HO}$.

Flexion-extension segmental range of motion (ROM) was measured at all affected levels. ROM was determined from differences between flexion and extension angles. This measurement was performed on digital radiograph images displayed on a PACS (Picture Achieve and Commu- nication System) terminal (Marosis 2003, Marotech, Seoul), and angles were measured using a program in PACS. In ACIF groups, the degree of bone fusion state was classified from grade 1 to 3 , based on the findings of dynamic lateral X-ray (Table 1).

Other specific radiological findings at the preoperative images including posterior longitudinal ligament (PLL) calcification or osteophyte at the operated level were also evaluated.

The presence of $\mathrm{HO}$ was determined and classified using McAfee classification system ${ }^{10)}$ in TDR groups. In ACIF groups, if there was more than $1 \mathrm{~mm}$ of any bone formation from the outmost border of vertebral body at last follow-up AP or lateral plain X-ray comparing to immediate postoperative images, this bone formation was determined as $\mathrm{HO}$ (Fig. 1).

The radiological assessments were performed twice by 2 independent observers. Inter- and intraobserver reliabilities of all radiological data were greater than a correlation of 0.80 .

\section{Statistics}

Comparing occurrence rate of $\mathrm{HO}$ between the subgroups 
Table 2. Demographic date of the patients

\begin{tabular}{|c|c|c|c|c|}
\hline & \multicolumn{2}{|c|}{ TDR } & \multicolumn{2}{|c|}{$\mathrm{AClF}$} \\
\hline & Bryan & Prodisc-C & Cage alone & Plate screw \\
\hline No. of cases & 17 & 23 & 29 & 18 \\
\hline Mean age (range) & $47.7(35-59)$ & $45.2(35-62)$ & $53.2(32-73)$ & $54.4(33-71)$ \\
\hline Gender (M:F) & $9: 7$ & 13:10 & 17:12 & 10:8 \\
\hline Mean F/U duration (range) & $31.4(24-37)$ & $28.1(24-32)$ & $30.4(25-37)$ & $32.7(24-38)$ \\
\hline No. of two level surgeries & 1 & 2 & 0 & 7 \\
\hline Total operated levels & 18 & 25 & 29 & 25 \\
\hline \multirow[t]{4}{*}{ Distribution of operated levels } & C45 (4) & C45 (6) & C34 (4) & C34 (3) \\
\hline & C56 (10) & C56 (12) & C45 (8) & C45 (6) \\
\hline & C67 (4) & C67 (7) & C56 (10) & C56 (11) \\
\hline & & & C67 (7) & C67 (5) \\
\hline
\end{tabular}

"Months

was done using t-test. The presence of $\mathrm{HO}$ was statistically was verified in relation to the parameters of the present study. The relation to segmental ROM in TDR groups and fusion grade in ACIF groups was evaluated using a Spearman's rank correlation coefficient. The correlation with the presence of preoperative specific radiological findings was assessed using Chi-square test. Numerical results were averaged. All numerical findings were expressed as means \pm SDs. Statistical verification was determined using PASW Statistics 18 (version 18.0.0; SPSS Inc., USA). A P-value at 0.05 was set as statistical significance

\section{RESULTS}

Cervical TDR was performed in 40 patients, and ACIF was done in 47 patients. There were 10 cases of two level surgeries, thus total levels operated was 97 . The demographic data of the patients of each subgroup were listed on Table 1 .

Mean ROMs at the last follow-up of each TDR subgroup were $7.8 \pm 4.7^{\circ}$ in Bryan, $3.89 \pm 1.77^{\circ}$ in Prodisc-C. Fusion status of ACIF groups was observed as 2 case of grade 1, 6 of grade 2 , and 21 of grade 3 in cage alone subgroup (grade 1; 6.9\%, grade $2 ; 20.7 \%$, and grade $3 ; 72.4 \%$ ) and no case of grade 1 , 4 of grade 2 , and 21 of grade 3 in plate screw subgroup (grade 2; $16.0 \%$, and grade $3 ; 84.0 \%$ ).

Among total 97 levels operated, $\mathrm{HO}$ was demonstrated at 27 levels. The occurrence of $\mathrm{HO}$ in each group was showed on Fig. 2. TDR-Bryan group showed $44.4 \%$ of $\mathrm{HO}$ occurrence and TDR-Prodisc-C group did 48.0\%, and there was no significant difference between two subgroups ( $p>0.05$ ). In ACIF group, ACIF-cage alone subgroup only presented $24.1 \%$ of $\mathrm{HO}$. There was no case presented $\mathrm{HO}$ in plate screw subgroup.

The preoperative osteophyte at the operated level obser-

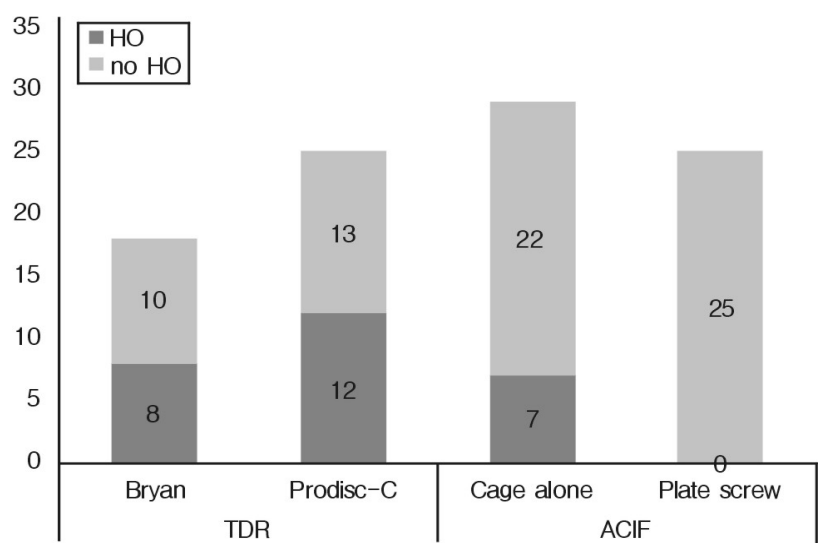

Fig. 2. Bar graphs showing the occurrence of $\mathrm{HO}$ in each group.

ved in 27 levels (TDR-Bryan; 5, TDR-Prodisc-C; 3, ACIF-cage alone; 11, ACIF-plate screw; 8). Among those 27 levels, HO was demonstrated in 14 levels (TDR-Bryan; 3 (60.0\%), TDR-Prodisc-C; 2 (66.7\%), ACIF-cage alone; 7 (63.6\%), ACIF-plate screw; 0).

Preoperative PLL calcification at the operated level was observed 22 levels (TDR-Bryan; 5, TDR-Prodisc-C; 5, ACIF-cage alone; 7, ACIF-plate screw; 5). HO was defined at 9 levels in TDR group (TDR-Bryan; 5 (100\%), TDR-Prodisc-C; 4 (90 $\%)$, and 5 levels in ACIF group ACIF-cage alone; 5 (71.4\%), ACIF-plate screw; 0).

The statistical verification between clinical variables of the present study and the occurrence of $\mathrm{HO}$ was listed on Table 3. The grade of fusion status, the evidence of preoperative osteophyte and PLL calcification were significantly related to the occurrence of HO. The final ROMs at the operated segment in TDR group did not correlate with the occurrence of $\mathrm{HO}$. $\mathrm{HO}$ occurrence in relation to fusion status in ACIFcage alone subgroup was listed on Table 4. 
Table 3. Relations between clinical variables and heterotopic ossification

\begin{tabular}{lccc}
\hline \hline \multirow{2}{*}{ Clinical variables } & \multicolumn{3}{c}{ p-value } \\
\cline { 2 - 4 } & Bryan & Prodisc-C & Cage alone \\
\hline Age & 0.281 & 0.455 & 0.632 \\
Sex & 0.578 & 0.722 & 0.588 \\
Level operated & 0.534 & 0.857 & 0.202 \\
Follow up duration & 0.278 & 0.455 & 0.896 \\
Preop FSU ROM & 0.725 & 0.367 & - \\
Postop FSU ROM & 0.244 & 0.399 & - \\
Grade of fusion status & - & - & 0.002 \\
Preop osteophyte & 0.000 & 0.000 & 0.000 \\
Preop PLL calcification & 0.000 & 0.000 & 0.000 \\
\hline
\end{tabular}

Table 4. $\mathrm{HO}$ occurrence in relation to fusion status in ACIF-cage alone subgroup

\begin{tabular}{lcc}
\hline \hline \multirow{2}{*}{ Fusion status } & \multicolumn{2}{c}{$\mathrm{HO}$} \\
\cline { 2 - 3 } & $\mathrm{NO}$ & Yes \\
\hline Grade 1 & 0 & 2 \\
Grade 2 & 3 & 3 \\
Grade 3 & 20 & 1 \\
\hline
\end{tabular}

\section{DISCUSSION}

In cervical TDR, $\mathrm{HO}$ has been considered as one of the major problems. Although the clinical significance of $\mathrm{HO}$ is not proved, it should diminish the motion at the index segment over time.

The precise etiology of $\mathrm{HO}$ is still unclear, but traumatic, neurogenic, and genetic factors are considered as major possible causes ${ }^{2,11}$. Among them, traumatic HO would follow fractures, severe burns, or operation procedures, and it is conceived that the differentiation of mesenchymal cells originating from skeletal system to osteoblasts plays a major role ${ }^{12}$. Mesenchymal cells releasing form the damaged muscle or bone may spread into surrounding soft tissue, evolve into osteoblast by stimulation of bone inducing agents such as BMP (bone morphogenetic protein) ${ }^{3,5,13)}$ or prostaglandin-E2 $2^{1,9,18)}$, and finally lead inevitable bone formation.

HO following cervical TDR has been considered to occur by traumatic cause. Thus, several intraoperative situations, such as bleeding at the keel cut site, rough soft-tissue dissection, and the remained bone dust following bone works are proposed as possible causal factors ${ }^{15,21)}$. However, these are not unique circumstances of cervical TDR only. All anterior cervical surgeries with standard approach require manipulation of soft tissues and bone to various degree. If we accepted the proposed pathogenesis of traumatic $\mathrm{HO}$, there would be a possibility of that $\mathrm{HO}$ could occur after all kinds of anterior cervical spine surgeries.

In the present study, TDR group showed high incidence rate of $\mathrm{HO}$ in two subgroups (Bryan: 44\%, Prodisc-C: 48\%). ACIF group which was operated with a stand-alone cage also showed $24.1 \%$ of $\mathrm{HO}$ occurrence rate, despite of no case presented $\mathrm{HO}$ in plate screw subgroup. Although the incidence is different, the present results indicate that $\mathrm{HO}$ is not a special event of TDR surgery. The occurrence rate of $\mathrm{HO}$ between two TDR subgroups is similar, but between the ACIF subgroups, there was a significant difference. An ACIF with standalone cage is a little simpler procedure than an ACIF with plate and screw fixation. Thus, the incidence of $\mathrm{HO}$ in cage alone group should be lower than plate screw subgroup according to the hypothesis of traumatic HO. However, the present study showed the opposite results which cage alone subgroup presented higher incidence.

In ACIF, it could be a debated issue whether the bone formation from the outmost border of vertebral body at the operated level is real $\mathrm{HO}$ or not. It could be concerned as one of fusion processes or a finding related to pseudoarthrosis. However, a typical fusion process in ACIF using an interbody cage would be more conducted inside of a cage rather than near the outmost vertebral body. In the present study, most of the case in ACIF group which was determined as HO showed the obvious bone formation in near outmost vertebral body than inside a cage. Pseudoathrosis means fusion failure. The remaining motion due to failed fusion could make a similar situation with an unsuccessful motion preserving surgery. Thus, we believe that bone formation near outmost vertebral body is real HO.

Many clinicians have emphasized that prevention of $\mathrm{HO}$ strongly depend on the degree of manipulation of soft tissue or bone during the procedure. Intraoperatively, therefore, careful dissection of soft-tissue, and meticulous hemostasis and cleaning operation field after bone works have been recommended to decrease incidence rate of HO. Yang et al. ${ }^{21)}$, reported only $6.7 \%$ of $\mathrm{HO}$ occurrence rate after cervical TDR with Bryan disc at a minimum of 24 months follow-up. They described that their best attempt at cleaning the operative site with normal saline and limiting retraction of cervical muscles would be effective in prevention of HO. However, practically most spine surgeons routinely have tried to minimize soft tissue injury and clean the field during the operation. And there have been much more reports to note the high incidence of HO following cervical TDR. Thus, we believe that there could be other factors affecting the occurrence rate of $\mathrm{HO}$ except for manipulation degree of soft tissue or bone.

The biomechanical studies in the cervical spine have revealed that fixations with stand-alone cage provide less stiffness than the plated method. Shimamoto et al. ${ }^{16}$, performed in 
vitro biomechanical investigation of the immediate stability in cervical reconstruction. They compared three different reconstruction methods; stand-alone cage (RABEA cage), tricortical autograft only, and additional locking plate and screws system by observing three-dimensional segmental range of motion at the operated segment. In flexion/extension, standalone cage group showed a significantly higher range of motion than did the other groups, and even than did intact spine. Hart et al. ${ }^{6}$, have conducted in vitro biomechanical comparison of a single threaded cylindrical interbody cage versus a plated fusion construct. They also observed that the specimens implanted with a cage showed significantly greater initial ROM and significantly less initial stiffness than in plated specimens. Cage specimens also failed at a significantly lower load than plated specimens. This low biomechanical property of standalone cage would affect fusion success rate. In the present study, cage alone subgroup showed low fusion rate (grade $1 ; 6.9 \%$, grade $2 ; 20.7 \%$, and grade $3 ; 72.4 \%$ ) compared to plate screw subgroup (grade $2 ; 16.0 \%$, and grade $3 ; 84.0 \%$ ). Song et al. ${ }^{17}$, reported similar results with the present study. In their study, ACIF performed with plate and screw fixation had better fusion rate and faster fusion time than ACIF with stand-alone cage. These above results mean that a fixation with standalone cage has more remaining motion postoperative immediately and over time compared to the plate screw group.

Following the present results, it seems that there is the remained motion after surgery, HO could occur. It could be supposed that a biomechanical stress related to motion is strongly related to developing HO. It has been well known that repetitive dynamic loads on bone may trigger bone remodeling. Thus, we suggested that a mechanical stimulation by constant dynamic load from the postoperative remaining motion regardless type of surgery is one of causal factors of HO. In the present study, the final ROMs at the operated segment in TDR subgroups was significantly different according to prosthesis type. However, both TDR subgroups showed the similar incidence of $\mathrm{HO}$. It suggested that occurrence rate of $\mathrm{HO}$ depends on whether the motion is remaining or not, not proportional the amount of motion remained.

Moreover, $\mathrm{HO}$ would be a normal defense mechanism of human body against non-physiologic motion. In physiologic situation, unacceptable motion of skeletal system could be eliminated by surrounding bone formation. If this hypothesis is received, the high incidence of $\mathrm{HO}$ in the most artificial discs popularly used indicates that the prostheses do not provide physiologic motion as like as normal disc. If prosthesis does not function as much as normal disc does, $\mathrm{HO}$ could be remained as an unavoidable problem, regardless of how much handles soft tissue or bone during an operation. In such case, prosthesis which provides normal physiologic motion would be only solution to prevent HO.

Preoperative osteophyte and PLL calcifications have been regar ded as a risk factor of $\mathrm{HO}^{4,14,15)}$. We also studied whether these preoperative constitutional factors affect postoperative occurrence of HO. In the present results, preoperative osteophyte and PLL calcifications were strongly correlated with postoperative development of $\mathrm{HO}$.

Preserving motion is the most important goal of TDR surgery. Thus, occurrence of $\mathrm{HO}$ has been seriously emphasized because of its relationship with loss of motion. Leung et al. ${ }^{8)}$, reported a strong association between the occurrence of $\mathrm{HO}$ and the loss of mobility of the operated segment of cervical TDR which is fatal to the effectiveness of TDR. To develop ideal prosthesis which could maintains motion in a long term, more effort to understand normal kinematics of disc would be needed.

\section{CONCLUSION}

In the present study, $\mathrm{HO}$ was observed in both TDR groups, and there was no difference of occurrence rate between two prosthesis types. In ACIF group, cage alone subgroup showed higher incidence of $\mathrm{HO}$ than the rigidly fixed plate screw subgroup. The results herald that not only iatrogenic factor such as postoperative biomechanical stress but constitutional properties such as preoperative calcification of longitudinal ligaments and osteophyte also play important role in the process of $\mathrm{HO}$ formation.

\section{REFERENCES}

1. Ahrengart L, Lindgren U, Reinholt FP: Comparative study of the effects of radiation, indomethacin, prednisolone, and ethane-1hydroxy-1, 1-diphosphonate (EHDP) in the prevention of ectopic bone formation. Clin Orthop Relat Res: p265-273, 1988

2. Balboni TA, Gobezie R, Mamon HJ: Heterotopic ossification: Pathophysiology, clinical features, and the role of radiotherapy for prophylaxis. Int J Radiat Oncol Biol Phys 65:1289-1299, 2006

3. Brooker AF, Bowerman JW, Robinson RA, Riley LH, Jr.: Ectopic ossification following total hip replacement. Incidence and a method of classification. J Bone Joint Surg Am 55:1629-1632, 1973

4. Eggli S, Woo A: Risk factors for heterotopic ossification in total hip arthroplasty. Arch Orthop Trauma Surg 121:531-535, 2001

5. Hannallah D, Peng H, Young B, Usas A, Gearhart B, Huard J: Retroviral delivery of Noggin inhibits the formation of heterotopic ossification induced by BMP-4, demineralized bone matrix, and trauma in an animal model. J Bone Joint Surg Am 86-A:8091, 2004

6. Hart R, Gillard J, Prem S, Shea M, Kitchel S: Comparison of stiffness and failure load of two cervical spine fixation techni- 
ques in an in vitro human model. J Spinal Disord Tech 18 Suppl: S115-118, 2005

7. Hrabalek L, Vaverka M, Houdek M: [Cervical disc arthroplasty (Prodisc-C): analysis of 3 to 4-year follow up results]. Rozhl Chir 88:634-641, 2009

8. Leung C, Casey AT, Goffin J, Kehr P, Liebig K, Lind B, et al: Clinical significance of heterotopic ossification in cervical disc replacement: a prospective multicenter clinical trial. Neurosurgery 57:759-763; discussion 759-763, 2005

9. Matta JM, Siebenrock KA: Does indomethacin reduce heterotopic bone formation after operations for acetabular fractures? A prospective randomised study. J Bone Joint Surg Br 79:959963, 1997

10. McAfee PC, Cunningham BW, Devine J, Williams E, Yu-Yahiro $\mathrm{J}$ : Classification of heterotopic ossification $(\mathrm{HO})$ in artificial disk replacement. J Spinal Disord Tech 16:384-389, 2003

11. McCarthy EF, Sundaram M: Heterotopic ossification: a review. Skeletal Radiol 34:609-619, 2005

12. Naraghi FF, DeCoster TA, Moneim MS, Miller RA, Rivero D: Heterotopic ossification. Orthopedics 19:145-151, 1996

13. Reddi AH: Bone morphogenetic proteins, bone marrow stromal cells, and mesenchymal stem cells. Maureen Owen revisited. Clin Orthop Relat Res: p115-119, 1995

14. Ritter MA, Vaughan RB: Ectopic ossification after total hip arthroplasty. Predisposing factors, frequency, and effect on results. J Bone Joint Surg Am 59:345-351, 1977

15. Ryu KS, Park CK, Jun SC, Huh HY: Radiological changes of the operated and adjacent segments following cervical arthroplasty after a minimum 24-month follow-up: comparison between the Bryan and Prodisc- $\mathrm{C}$ devices. J Neurosurg Spine 13: 299-307, 2010

16. Shimamoto N, Cunningham BW, Dmitriev AE, Minami A, McAfee PC: Biomechanical evaluation of stand-alone interbody fusion cages in the cervical spine. Spine (Phila Pa 1976) 26:E432-436, 2001

17. Song KJ, Taghavi CE, Lee KB, Song JH, Eun JP: The efficacy of plate construct augmentation versus cage alone in anterior cervical fusion. Spine (Phila Pa 1976) 34:2886-2892, 2009

18. Spencer RF: The effect of head injury on fracture healing. A quantitative assessment. J Bone Joint Surg Br 69:525-528, 1987

19. Tortolani PJ, Cunningham BW, Eng M, McAfee PC, Holsapple GA, Adams KA: Prevalence of heterotopic ossification following total disc replacement. A prospective, randomized study of two hundred and seventy-six patients. J Bone Joint Surg Am 89:82-88, 2007

20. Walraevens J, Demaerel P, Suetens P, Van Calenbergh F, van Loon J, Vander Sloten J, et al: Longitudinal prospective longterm radiographic follow-up after treatment of single-level cervical disk disease with the Bryan Cervical Disc. Neurosurgery 67: 679-687; discussion 687, 2010

21. Yang YC, Nie L, Cheng L, Hou Y: Clinical and radiographic reports following cervical arthroplasty: a 24-month follow-up. Int Orthop 33:1037-1042, 2009 